\title{
Exploring the Variation in Ontario Nursing Home Prescribing Rates for Antipsychotics
}

Paula A. Rochon

\section{The Issue}

Antipsychotic therapy is often used to manage behavioural and psychological symptoms of dementia and psychosis, particularly when these problems pose risks to the resident or others. Yet there exists concern about inappropriate and widespread prescribing of antipsychotic therapy in many nursing homes. Conventional antipsychotics, available since the 1950s, are associated with serious adverse events such as falls, hip fractures and Parkinsonism. The newer "atypical" antipsychotic drugs, which were thought to be safer when released in the 1990s, have been linked to Parkinsonism, other movement disorders and death. Although specific indications exist for antipsychotic therapy in elderly nursing home residents, non-drug therapy should be recommended as first-line therapy where appropriate. In fact, the decision to initiate therapy should be reserved for situations where the benefits outweigh the risks. The relatively homogeneous group of residents in Ontario nursing homes provides an opportunity to examine the variation in the prescribing patterns of antipsychotics across facilities and in relation to specific clinical indications.

\section{The Study}

In a recent study, scientists at the Institute for Clinical Evaluative Sciences (ICES) explored the variation in the use of antipsychotic drugs across Ontario nursing homes. Nursing home residents aged 66 years and older on December 1, 2003, were identified, and a total of 47,322 residents in 485 provincially registered nursing homes across Ontario were included in the study. The percentage of residents who were dispensed antipsychotic drugs at each nursing home was calculated. Nursing homes were then classified into quintiles (Q1-Q5), based on their mean facility-level antipsychotic prescribing rates, with Q1 being the quintile with the lowest mean prescribing rates and Q5 being the quintile with the highest. In addition, all residents were divided into three mutually exclusive clinical groups: two that were considered to have potential clinical indications for antipsychotic therapy (psychoses with or without dementia; dementia without psychoses) and a third group with no clinical indication for treatment. In this latter group, antipsychotic therapy would be considered inappropriate.

\section{Key Findings}

A total of 15,317 (32.4\%) residents were dispensed an antipsychotic drug, while the average rate of prescribing ranged from 20.9 to $44.3 \%$, in Q1 and Q5, respectively (Table 1). Relative to individuals residing in nursing homes with the lowest average prescribing rates, those residing in facilities with the highest rates were three times more likely to be dispensed antipsychotics (odds ratio, 3.0; 95\% confidence interval, 2.77-3.16). This threefold higher rate persisted when adjustments were made for facility (size and setting) and resident characteristics (age, gender, comorbidities and total drug count; Table 2). The same pattern was seen within each clinical indication group, regardless of whether there was a potential clinical indication for the medications (see Table 2).

\section{The decision to initiate therapy should be reserved for situations where the benefits outweigh the risks.}

\section{What Do These Findings Mean?}

One-third of the nursing home residents were dispensed an antipsychotic drug, which is even higher than the rate previously reported. There is a strong relationship between being in a nursing home with a high or low prescribing rate for antipsychotics and the chance of being prescribed an antipsychotic therapy, regardless of other facility or resident characteristics. In addition, the decision to prescribe an antipsychotic therapy does not appear to be solely related to a resident's clinical condition but may be also influenced by other factors.

\section{Conclusion}

There remains uncertainty about the overall benefit of antipsychotic therapy in elderly nursing home residents, and this study provides support for the existence of significant variations in prescribing practices across Ontario nursing homes. Given that antipsychotics have been linked to important safety concerns, these results provide an opportunity for nursing homes to reflect 
Table 1. Nursing home and residents' characteristics, by antipsychotic drug therapy prescribing rate quintiles

\begin{tabular}{|c|c|c|c|c|c|c|c|}
\hline & \multirow{2}{*}{$\begin{array}{l}\text { Overall } \\
\text { n (\%) }\end{array}$} & \multicolumn{5}{|c|}{ Antipsychotic Drug Therapy Prescribing Rate Quintile, n (\%) } & \multirow{2}{*}{$\begin{array}{l}\text { Rate Ratio, } \\
\text { Q5:Q1 (95\% } \\
\text { Cl) }\end{array}$} \\
\hline & & Q1* & Q2 & Q3 & Q4 & Q5† & \\
\hline \multicolumn{8}{|l|}{ Characteristics } \\
\hline Facilities & 485 & $104(21.4)$ & $98(20.2)$ & $84(17.3)$ & $91(18.8)$ & $108(22.3)$ & NA \\
\hline Residents & 47,322 & $9,421(19.9)$ & $9,572(20.2)$ & $9,255(19.6)$ & $9,854(20.8)$ & $9,220(19.5)$ & NA \\
\hline $\begin{array}{l}\text { Prescribed any } \\
\text { antipsychotic }\end{array}$ & $15,317(32.4)$ & $1,965(20.9)$ & $2,685(28.1)$ & $3,002(32.4)$ & $3,581(36.3)$ & $4,084(44.3)$ & NA \\
\hline \multicolumn{8}{|l|}{ Clinical groups } \\
\hline \multicolumn{8}{|l|}{$\begin{array}{l}\text { Potential clinical indication for } \\
\text { antipsychotic therapy }\end{array}$} \\
\hline $\begin{array}{l}\text { Psychoses, with or without } \\
\text { dementia }\end{array}$ & $10,247(21.7)$ & $1,650(17.5)$ & $2,058(21.5)$ & $2,165(23.4)$ & $2,261(22.9)$ & $2,113(22.9)$ & $1.31(1.26-1.35)$ \\
\hline Dementia, without psychosis & $29,017(61.3)$ & $5,940(63.1)$ & $5,883(61.5)$ & $5,455(58.9)$ & $6,059(61.5)$ & $5,680(61.6)$ & $0.98(0.95-1.00)$ \\
\hline $\begin{array}{l}\text { No potential clinical } \\
\text { indication for antipsychotic } \\
\text { therapy } \ddagger\end{array}$ & $8,058(17.0)$ & $1,831(19.4)$ & $1,631(17.0)$ & $1,635(17.7)$ & $1,534(15.6)$ & $1,427(15.5)$ & $0.80(0.72-0.88)$ \\
\hline
\end{tabular}

NA = Not applicable.

*Lowest antipsychotic prescribing rate.

tHighest antipsychotic prescribing rate.

$\ddagger$ No psychoses or dementia.

One-third of the nursing home residents were dispensed an antipsychotic drug.

Table 2. Resident-level use of antipsychotic therapy, by clinical group and antipsychotic drug therapy prescribing rate quintiles

\begin{tabular}{|l|l|l|l|l|l|}
\hline \multirow{2}{*}{$\begin{array}{l}\text { Potential Clinical Indication for Use of } \\
\text { Antipsychotic Therapy }\end{array}$} & \multicolumn{3}{|l|}{ Adjusted* Odds Ratio (95\% CI) } & $\mathbf{0}$ & $\mathbf{0 4}$ \\
\cline { 2 - 7 } & $\mathbf{0 1 \dagger}$ & $\mathbf{0 2}$ & $\mathbf{0 3}$ & $\mathbf{0 . 5 \ddagger}$ \\
\hline Psychoses, with or without dementia & $1.0 \S$ & $1.3(1.16-1.55)$ & $1.6(1.41-1.88)$ & $1.9(1.71-2.22)$ & $2.7(2.35-3.09)$ \\
\hline Dementia, without psychosis & $1.0 \S$ & $1.5(1.36-1.62)$ & $1.8(1.68-2.01)$ & $2.1(1.96-2.35)$ & $3.1(2.81-3.39)$ \\
\hline No psychoses or dementia & $1.0 \S$ & $1.4(1.07-1.86)$ & $1.8(1.35-2.49)$ & $2.0(1.51-2.64)$ & $2.9(2.19-3.81)$ \\
\hline All clinical groups & $1.0 \S$ & $1.4(1.32-1.53)$ & $1.8(1.65-1.91)$ & $2.1(1.93-2.21)$ & $3.0(2.74-3.19)$ \\
\hline
\end{tabular}

${ }^{*}$ Adjusted for facility and residents' characteristics.

tLowest antipsychotic prescribing rate.

¥Highest antipsychotic prescribing rate.

§Reference. 
on their prescribing practices and to determine whether they can be improved. In addition, information about variations in prescribing rates of antipsychotics across the province makes it possible for nursing homes with low rates to share their successful behaviour management strategies with other nursing homes. As such, the quality of patient care for Ontario nursing home residents can be improved. HQ

\section{Bibliography}

Bronskill S.E, G.M. Anderson, K. Sykora, W.P. Wodchis, S. Gill, K.I. Shulman and P.A. Rochon. 2004. "Neuroleptic Drug Therapy in Older Adults Newly Admitted to Nursing Homes: Incidence, Dose, and Specialist Contact." Journal of the American Geriatrics Society 52: 749-55.

Gill, S.S., S.E. Bronskill, S.-L.T. Normand, G.M. Anderson, K. Sykora, K. Lam, C.M. Bell, P.E. Lee, H.D. Fischer, N. Herrmann, J.H. Gurwitz and P.A. Rochon. 2007. "Antipsychotic Drug Use and Mortality in Older Adults with Dementia." Annals of Internal Medicine 146: 775-86.

Lee, P.E., K. Sykora, S.S. Gill, M. Mamdani, C. Marras, G. Anderson, K.I. Shulman, T. Stukel, S.L. Normand and P.A. Rochon. 2005. "Antipsychotic Medications and Drug-Induced Movement Disorders Other than Parkinsonism: A Population-Based Cohort Study in Older Adults." Journal of the American Geriatrics Society 53: 1374-79.

Rochon, P.A., T.A. Stukel, K. Sykora, S. Gill, S. Garfinkel, G.M. Anderson, S.L. Normand, M. Mamdani, P.E. Lee, P. Li, S.E. Bronskill, C. Marras and J.H. Gurwitz. 2005. "Atypical Antipsychotics and Parkinsonism.” Archives of Internal Medicine 165: 1882-88.

Rochon, P.A., T.A. Stukel, S.E. Bronskill, T. Gomes, K. Sykora, W.P. Wodchis, M. Hillmer, A. Kopp, J.H. Gurwitz and G.M. Anderson. 2007. "Variation in Nursing Home Antipsychotic Prescribing Rates." Archives of Internal Medicine 167: 676-83.

\section{About the Author}

Paula A. Rochon, MD, MPH, is a senior scientist at ICES, a geriatrician and senior scientist at the Kunin-Lunenfeld Applied Research Unit at Baycrest, and a professor of Medicine and Health Policy, Management and Evaluation at the University of Toronto. The work described in this article was supported by a Canadian Institutes of Health Research (ClHR) operating grant (MOP-53124), a ClHR Chronic Disease New Emerging Team program (NET-54010) and an Interdisciplinary Capacity Enhancement grant (HOA-80075). For more information, contact paula.rochon@utoronto.ca.

\section{Thank you}

for supporting Breakfast with the Chiefs

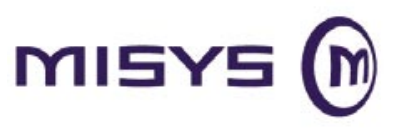

Longwoods Publishing Enabling Excellence

\section{Health Council of Canada Appoints New Chief Executive Officer}

Dr. Jeanne Besner, Chair of the Health Council of Canada, is pleased to announce the appointment of Dr. Donald W. M. Juzwishin as Chief Executive Officer, effective Sept. 1, 2007. Dr. Juzwishin brings 28 years of leadership and management experience to the Health Council of Canada. His background

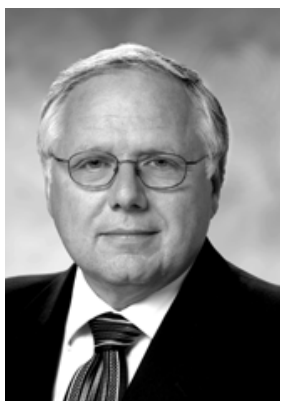
includes knowledge in health care management, policy making, education and research.

Most recently a private consultant in health care policy in St. Albert, Alberta, Dr. Juzwishin also served as the Director of Health Technology Assessment at the Alberta Heritage Foundation for Medical Research. Prior to that, he was with the Ministry of Health in British Columbia where he introduced the province's first accountability and performance measures framework to monitor and report on health reform in the province. He has held executive positions at the Royal Alexandra Hospital in Edmonton, Alberta and at the Greater Victoria Hospital Society in Victoria, British Columbia.

Dr. Juzwishin received his $\mathrm{PhD}$ in education policy studies from the University of Alberta and has adjunct appointments at the University of Victoria, Health Information Science; University of Alberta, School of Public Health; and University of Calgary, Community Health Sciences. He has served as a board member and chair of the Canadian Coordinating Office for Health Technology Assessment (now the Canadian Agency for Drugs and Technology in Health). Dr. Juzwishin has published extensively with more than 100 publications to his credit and has spoken nationally and internationally in his areas of specialization.

\section{Background}

The Health Council of Canada, created by the 2003 First Ministers' Accord on Health Care Renewal following the recommendations of the Romanow and Kirby reports, is mandated to monitor and report on the progress of health care renewal in Canada. The 26 Councillors were appointed by the participating provinces, territories and the Government of Canada and have expertise and broad experience in community care, Aboriginal health, nursing, health education and administration, finance, medicine and pharmacy. 


\section{MEDEC}

CANADA'S MEDICAL DEVICE TECHNOLOGY COMPANIES

LES SOCIÉTÉS CANADIENNES DE TECHNOLOGIE DES

DISPOSITIFS MÉDICAUX

\section{WHEN HEALTH CARE PROFESSIONALS SEE THE MEDEC CODE OF CONDUCT SYMBOL \\ THEY WILL KNOW THAT THE COMPANY HAS AN ACTIVE CODE OF ETHICS GOVERNING QUALITY, PROFESSIONALISM AND BEST PRACTICES.}

\section{PARTICIPANT OF THE \\ www.medec.org/code \\ CODE OF \\ CONDUCT \\ PARTICIPANT

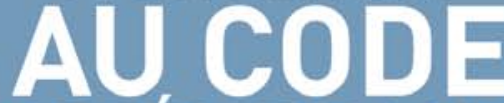 \\ DE DÉONTOLOGIE \\ www.medec.org/code}

We see the MEDEC Code of Conduct as becoming the recognized standard for the medical device industry in Canada and acknowledge our charter licencees.
3M Health Care
ARJO
(20.7) Bayer HealthCare
@ $\beta M$
BD

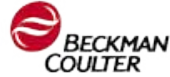

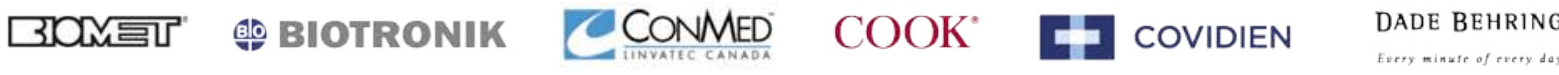

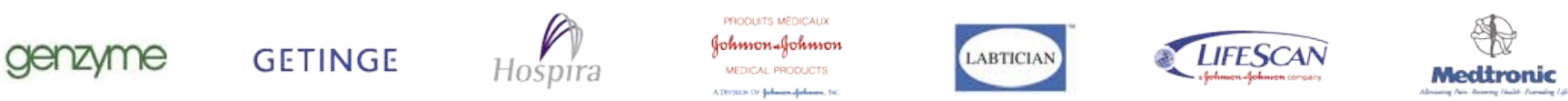

Roche H SORINGROUP ST.JUDE MEDICAL * STEVENS $\square$ STRATUM WRIGHT. 